\title{
An Exploratory Study of RFID Adoption in the Paperboard Packaging Industry
}

\author{
B. S.Vijayaraman (I), Barbara A. Osyk (2), \\ Dhanraj Chavada (3)
}

\begin{abstract}
Some experts predict RFID will be the next big technology to revolutionize supply chain management. The RFID mandates by the Department of Defense (DOD), Federal Drug Administration (FDA), and retail companies have required organizations to implement RFID technology. Other companies are evaluating the potential costs and benefits of such adoption. In order to establish benchmarks on RFID adoption, this study surveyed readers of Paperboard Packaging magazine and members of the European Federation of Corrugated Board Manufacturers (FEFCO) to see if they are implementing RFID technology and challenges they may face. The results indicate about $52 \%$ of responding companies are not currently considering RFID technology because of the cost concerns. Companies that are implementing or considering RFID are doing it because of their customer requirements although they are concerned about the cost of RFID tags and cost of implementation. Companies that are implementing RFID are somewhat satisfied with RFID implementation.
\end{abstract}

Keywords: RFID, Supply Chain Management, Paperboard Packaging,Adoption

(I) Professor of Management \& IS. Department of Management. College of Business Administration. The University of Akron, Akron, $\mathrm{OH}$ 44325-480I.330-972-8224.vijay@uakron.edu

(2) Associate Professor of Management. Department of Management. College of Business Administration. The University of Akron. Akron, OH 44325-480I.330-972-5439.bao@uakron.edu

(3) Department of Management. College of Business Administration. The University of Akron.Akron, OH 44325-480I. dnc4@uakron.edu 


\section{Introduction}

Radio Frequency Identification (RFID) has generated much buzz in the supply chain arena. The technology itself is not new, and it has been used in various applications for more than 20 years. However, the technology is maturing and costs are continuing to decrease. Increasingly RFID is viewed as a tool to track the movement of items throughout a supply chain, not just within a facility (Hugos, 2006). RFID has the potential to add value across the entire supply chain. Both manufacturing and retail operations have the opportunity to be involved with the adoption of this technology. While much of the research to date has been focused on the retail industry, increasingly research suggests that RFID applications will be taking off in many other diverse industries including transportation, aerospace, utilities, and defense, to name a few (Bendavid, Lefebvre, Lefebvre, Fosso-Wamba, 2009; Bhattacharya, Chu and Mullen, 2008; Das, 2007; White, Johnson, and Wilson, 2008). One such industry seriously considering the adoption of RFID technology is the Paperboard Packaging Industry (Andel, 2005). Experts believe that many opportunities exist for early adopters of RFID technology within this industry. While numerous studies (Aberdeen Group 2006; Boeck and Fosso Wamba, 2007; Loebbecke and Palmer, 2006; Fosso Wamba, Lefebvre, Bendavid, Lefebvre, 2007; Vijayaraman and Osyk, 2006) have been conducted to study the impact of RFID technology on other portions of the supply chain including retailers and consumer goods companies, not much work has been published regarding the impact of RFID technology on packaging providers.

A review of the case study material available to date indicates that early adopters in the packaging industry are uncovering real bottom line benefits from the use of RFID within their own operations and that further benefits arise when integrating applications with their trading partners (Poirier and McCollum, 2006). However, not all in the supply chain have looked at RFID as a strategic enabler.A majority of the early adopters have implemented RFID because of the mandate by their business partners. These adopters have simply looked at RFID as a technology upgrade and an added cost of doing business with no $\mathrm{ROI}$ in the near future.

In order to keep the deployment cost down and meet the compliance mandated by their business partners, many implementers have adopted the "slap and ship" approach to RFID technology deployment (Vijayaraman and Osyk, 2006). Since such an approach applies RFID tags at the last step in the fulfillment process, it limits the ability of a business to exploit the technology through its supply chain process and realize a positive ROI. White, Johnson, and Wilson (2008) found that companies employing a "slap and ship" approach did not expect the same benefits as those that integrated RFID into their enterprise systems.
A number of packaging companies, like other manufacturing companies have been mandated by their customers to implement RFID at the case and pallet level. Apart from this some of the packaging companies are exploring the option of embedding RFID tags in the individual packages such as cardboard cartons so that they can meet the mandates by the retail company without spending money on RFID tag applicators. According to Andel (2005), with rapid adoption of RFID technology in the consumer product goods industry, it is possible that these mandated suppliers and manufacturers would request packages with already applied or embedded RFID tags from their packaging providers. This presents double the challenge for companies in the packaging industry compared to companies in the manufacturing industry.

\section{Strategic uses of RFID technology}

It is difficult to determine the extent to which packaging companies are strategically using RFID within their organizations. Many of the reported benefits of RFID are anecdotal. Angeles (2005) cites a number of benefits realized or anticipated by diverse organizations including Unilever, United Biscuits, the Port of Singapore, and Toyota. These organizations and others have reportedly realized benefits in time savings, improved workflow, better tracking, and improved quality. From a business process standpoint, supply chain adopters, including packaging providers, stand to derive several potential benefits from RFID. First, within the company's warehouses, RFID can improve receiving, picking, and shipping accuracies (Asif and Mandviwalla, 2005). This could in turn facilitate greater efficiencies in shipping and receiving of goods. Second, improving inventory visibility decreases stock failures (Moran, Ayub, and McFarlane, 2003). Benefits can be gained here with improved ability to track goods and savings of assets as well as eliminating loss of revenues through out-of-stock conditions. Industry research has also shown that retail shrink levels historically are approximately two percent of sales, costing retailers an estimated $\$ 32$ billion in the USA and some $\$ 30$ billion in Europe in 200 I (Hidaka, 2005). RFID is expected to have drastic effects in reducing the amount of shrinkage and claims/thefts occurring in the retail environment and other delivery processes.

Further, by automating data collection, businesses can eliminate the manual data entry and manual business process transactions. This can provide significant benefits in terms of labor efficiency and overall cost reduction. Since with RFID the data captured from the tags is sharable by the business partners and could be made available in real-time, closer connections with supply chain partners are possible. This could provide for realtime visibility into customer purchase decisions in value chains, which in turn can position businesses to react more quickly to market trends. 
RFID technology is often cited as an alternative to and eventual replacement for bar codes, although it has been argued that there is a lack of empirical evidence to support this claim (White, Gardiner, Prabhakar, Razak, 2007). Some of the advantages of RFID technology over the use of bar codes include the fact that RFID does not require line of sight and it can potentially be read at large distances (Clampitt, 2009). This would be an advantage in the packaging industry where the tags may not be visible. RFID has other advantages over bar coding, including the potential for a longer lifespan, the ability to withstand harsh environments, and the increased traceability capabilities. The main disadvantage compared to bar codes is the high cost of RFID technology, including the cost of tags, readers, and the necessary software. However it has been argued that the various benefits of RFID in the supply chain including reduced shrinkage, better visibility, and better protection against counterfeiting, improved stock management, and reduction in labor costs, must also be considered (Lewis, 2005). These and other potential cost savings should be considered when determining the ROI of an RFID implementation.

So where do packaging providers fit in with respect to the benefits in the overall supply chain? What is their role in contributing to the value proposition that RFID might have to offer in the supply chain? The Aberdeen Group (2004) research suggests that RFID benefits will vary depending on the type of enterprise. They suggest that one of the most promising areas of application will be for manufacturers of high value and low volume products (such as pharmaceutical distribution). Also, in cases where retailers create mixed pallets also may result in high value. On the other hand, distribution centers receiving many mixed pallets may not see much value in using RFID. So perhaps the packaging industry may or may not be able to make much of a contribution, depending on where in the process its services are required. Packaging provided to distribution centers receiving mixed pallets may be of no value, while packaging provided to manufacturers of high-value products may be of significant value.

\section{Challenges of RFID technology}

Despite potential benefits, many companies continue to implement RFID based on compliance rather than based on ROI (Warehousing Education and Research Council, 2006).This can be attributed to several reasons. Lack of demand from business customers has been one major reason. Since the technology demands large initial investments, little incentives exist for organizations that see no customer demand for RFID. Another challenge to RFID adoption is the lack of worldwide tag standards. The standards for RFID technology are still evolving. EPCglobal, a non-profit organization, is working with member organizations to establish standards for tags. Retailers such as
Wal-Mart, Target, Tesco, etc. are requiring suppliers to use the EPC standards (Vijayaraman and Osyk, 2006). In the packaging industry itself, a number of operational and technical concerns have been raised regarding the limitation of RFID systems (Albright, 2006).

These concerns continue to represent a challenge to the packaging providers in deploying RFID technology. The placement of tags on the packages for readability is one such concern. According to Clarke, Twede, Tazelaar and Boyer (2006), even though tag orientation has little effect on readability for empty cases, when a product such as rice or bottled water is added, tag orientation has a great effect on readability. The overall cost of implementation is another major factor in determining the speed at which RFID technology is adopted. RFID system requires expenditures for tags, readers, hardware, software, and system maintenance. Within the packaging industry, significant cost additions to packaging operations are seen as a concern.

Achieving a positive ROI on RFID implementations in the supply chain continues to be a challenge for many organizations. The cost of high technology is still the make or break issue for many packaging suppliers and their customers (Andel, 2005).A primary cost component of RFID technology is the repetitive cost of RFID tags. Additionally, companies considering RFID need to plan for additional network infrastructure, storage capacity, RFID printers and readers, and additional data generated by millions of new tags flowing in its supply chain (Asif and Mandviwalla, 2005). With regard to the cost, the recent focus within the supply chain industry has been on low cost RFID tags. Over I.3 billion RFID tags were produced in 2005, and by 2010 that figure is expected to soar to 33 billion reports InStat (Mumford, 2006). With the anticipated scale and scope of RFID deployments, tag costs are expected to continue their decline. However, even at low cost, they are a significant investment for packaging providers since they represent a recurring cost for them in an open supply chain. As discussed earlier, some feasible benefits which have the potential to improve ROI for packaging providers include an improved ability to track packages, greater efficiencies in shipping and receiving, claims/theft reduction, out of stock reductions, inventory reduction, labor efficiency and closer connection with supply chain partners.

According to Mahna (2005), the use of RFID will demand more flexible processing systems irrespective of whether the packaging is done at the production facility or at a co-packer. This will have a direct impact on the operational efficiency and profitability of the packaging company. For instance, if packaging suppliers were to consider adding tags to their boxes and displays, each tag would have to be individually identified and placed according to a specific product packaging level. This would require each batch of material to be specifically designed for the ulti- 
mate product packaging level and would require a certain placement precision (Andel, 2005). In addition, the presence of products or packaging containing metal components that block the RFID signal, or conveyor belts made up of static producing nylon, or glass fiber that produces radio noise may necessitate expensive changes in the physical infrastructure, thereby increasing costs (Margulius, 2004).

System integration has been another major concern for adopters. The challenge of RFID implementation comes from integrating RFID systems and the data they generate with other functional databases and applications (Jones, Clark-Hill, Shears, Comfort, and Hillier, 2004). Presently, since a majority of the adopters are building their own RFID system from parts offered by different vendors, they are faced with the additional challenge of integrating these systems with their internal database and ERP systems. Given the vast amount of data involved, capturing and communicating the data among disparate systems is a major concern. A survey by Cap Gemini Ernst \& Young of 275 respondents working in the packaging industry revealed that 46 percent of the respondents consider integration as the single biggest concern with RFID (Ferguson, 2004). Lack of standards is yet another concern for packaging converters. To derive benefits from their RFID investments, supply chain partners need to use similar tags, readers and operational frequencies. According to Whitaker, Mithas, \& Krishnan (2007), the lack of RFID standards leads to a delay in realizing a return on investment of RFID technology. While standardization of information formats placed on the RFID consumables have gained wide support with the Electronic Product Code (EPC) in the retailing industry; standards dealing with RFID frequency and protocols for the communication of readers and consumables such as tags and labels are continuously evolving. The lack of technology uniformity and standards has kept the overall cost of implementation high and is a concern for the packaging suppliers.

\section{Embedding of RFID tags in packages}

The trend towards embedded RFID tags in the packaging material is gaining momentum within the packaging industry. A popular trend is smart packaging, which involves the use of chemical, electrical, electronic, or mechanical technology, adding numerous features and functions to packaging (NanoMarkets, 2006). Smart packaging is expected to consume $\$ 1.1$ billion in printable and chip-based RFID tags by 201 I (RFid Gazette, 2006). For packaging suppliers, though, embedding these tags within their packages may pose challenges during the corrugating process. A bigger challenge could be the placement of tags, considering the chance the tag could be cut off or diecut out (Palmieri, 2006).
Despite the concerns and challenges, there is little doubt that tremendous market opportunity exists for packaging providers given their market customer relationships and expertise in product labeling. Even though the cost may outweigh the returns at this point, RFID provides an ideal platform for packaging providers to offer added value to their customers. With the advent of newer printing technologies and RFID adoption by multiple participants in the supply chain, RFID embedded packaging may prove to be a very attractive option for the customers facing the mandates.

According to Roberti (2006), end users want to move toward embedding RFID in cartons for shipping cases rather than applying labels. Some packaging companies such as Georgia Pacific, Smurfit Stone, and Weyerhauser have begun to research how to embed RFID tags in corrugate but the vast majority of the industry is behind. According to O'Connor (2006), TI and Smurfit-Stone Container Corporation have co developed a prototype consisting of corrugated cardboard case containing an integrated RFID inlay made with an antenna printed directly into the case with conductive ink. The companies predict that using packaging materials with integrated RFID tags could save labor and materials costs for consumer packaging goods companies since doing so would eliminate the need to purchase separate RFID labels and place them on cases. According to Smurfit-Stone Company, despite the low demand for RFID integrated packaging today, the demand will rise as tagging mandates and the number of goods that must be tagged continue to grow. Therefore, in order to be cost effective, consumer packaging companies are going to move to the embedded approach (O’Connor, 2006)

In an effort to determine the extent to which packaging companies are pursuing these potential benefits, a research study was undertaken. The rest of the paper discusses the analysis of the data collected from Paperboard Packaging companies in the US and Europe and highlights the benefits, challenges, future trends, and implications of RFID in the Paperboard Packaging industry.

\section{Methodology}

A research study was undertaken to determine the extent to which the Paperboard Packaging industry has adopted this technology to date and to determine what problems they have faced. In February and March of 2006, emails with links to a web-based RFID survey were sent to U.S. readers of Paperboard Packaging magazine and to members of the European Federation of Corrugated Board Manufacturers (FEFCO), requesting they fill out the survey. One follow up reminder was sent to each group approximately three weeks later. A web-based survey was chosen because it was an effec- 
tive means of collecting data from the targeted group of Paperboard Packaging magazine readers. Other reasons for using a web-based survey were lower cost, time savings, automated data capture for analysis, and the flexibility to ask only relevant questions in each of the adoption categories. The respondents included the following:

\section{Geography}

A total of 174 companies participated in this survey. Of the I 74 companies that participated, I 36 companies were from the US and the remaining 38 companies were from Europe.

\section{Job Title/Function}

A majority of the participants who responded (81\%) were in the management category and the rest were in the supervisory or staff specialist category. The largest percentage of survey respondents were owners (I3.8\%), general managers (I $2.6 \%)$, presidents \& vice presidents (I $2.6 \%)$, and sales managers $(9.8 \%)$.
Industry

Fifty-two percent of the companies who participated in the survey were independent corrugated or folding carton converters, and $32 \%$ of the companies were integrated converters of corrugated and/or folding carton, or rigid box converters. A majority of these companies provide packaging products to consumer packaged goods and food products industry. Only a small number of companies provide packaging products to the apparel industry. Most of the companies surveyed have more regional sales and manufacturing presence and were evenly distributed between national and international sales and manufacturing.

\section{Company Size}

The size of the companies ranged from small to very large, in both annual revenue and number of employees. The largest percentage $(55 \%)$ of these companies were small with annual revenue for 2005 of less than $\$ 50$ million, followed by companies with annual revenue of 50 million to $\$ 100$ million (13\%)

\begin{tabular}{|c|c|c|c|c|c|}
\hline & Implementing & Pilot Testing & Considering & Not Considering & Total \\
\hline US & 11 & 5 & 44 & 76 & 136 \\
\hline Europe & 0 & 5 & 19 & 14 & 38 \\
\hline Total & 11 & 10 & 63 & 90 & 174 \\
\hline Percentage & $6 \%$ & $6 \%$ & $36 \%$ & $52 \%$ & $100 \%$ \\
\hline
\end{tabular}

and $\$ 100$ million to $\$ 500$ million (I $2 \%$ ). Only $14 \%$ of the companies surveyed reported annual sales of more than $\$$ I billion. A majority of the responding companies (69\%) were small, with fewer than 500 employees, where 10\% of the responding companies were very large, with more than 10,000 employees.

\section{Data Analysis and Findings}

Table I indicates the status of RFID implementation among the companies surveyed. A very small percentage of respondents (I $2 \%)$ are either pilot testing or implementing RFID. Fifty-two

\begin{tabular}{|c|c|c|c|c|c|}
\hline Revenue & Implementing & Pilot Testing & Considering & $\begin{array}{c}\text { Not } \\
\text { Considering }\end{array}$ & Total \\
\hline Less than $\$ 50$ Million & 1 & 2 & 24 & 69 & 96 \\
\hline$\$ 50$ to $\$ 100$ Million & 1 & 3 & 8 & 10 & 22 \\
\hline$\$ 100$ Million to $\$ 500$ Million & 3 & 1 & 10 & 6 & 20 \\
\hline$\$ 500$ Million to \$I Billion & 0 & $\mathrm{I}$ & 8 & 1 & 10 \\
\hline \$I Billion to \$5 Billion & 2 & 0 & 7 & 2 & 11 \\
\hline More than \$5 Billion & 4 & 3 & 5 & 1 & 13 \\
\hline Total & 11 & 10 & 62 & 89 & 172 \\
\hline
\end{tabular}


percent of the respondents are not considering implementing RFID technology in the near future whereas $36 \%$ of the companies are at least considering implementing RFID during the next couple of years. All the companies that are implementing RFID are in the US and the companies that are pilot testing are evenly split between the US and Europe.

Table 2 indicates the breakdown of the status of RFID implementation among companies by their annual revenue. Over half of the companies who are implementing RFID have rev- enues of more than $\$$ I billion. However, a majority of companies with revenues of $\$ 50$ million or above are at least considering the implementation of RFID. Only in the smallest companies (less than $\$ 50$ million) did a majority (69 out of 96 ) respond that they were not considering the technology. So it would appear that this technology is of interest to all but the smallest companies. This is consistent with the InformationWeek 500 survey analyzed by Whitaker, et. al. (2007). They found the company's revenue was positively correlated with RFID adoption, implying that large firms are more likely to adopt RFID.

Figure 1: Concems of Companies that are Considering RFID Implementation

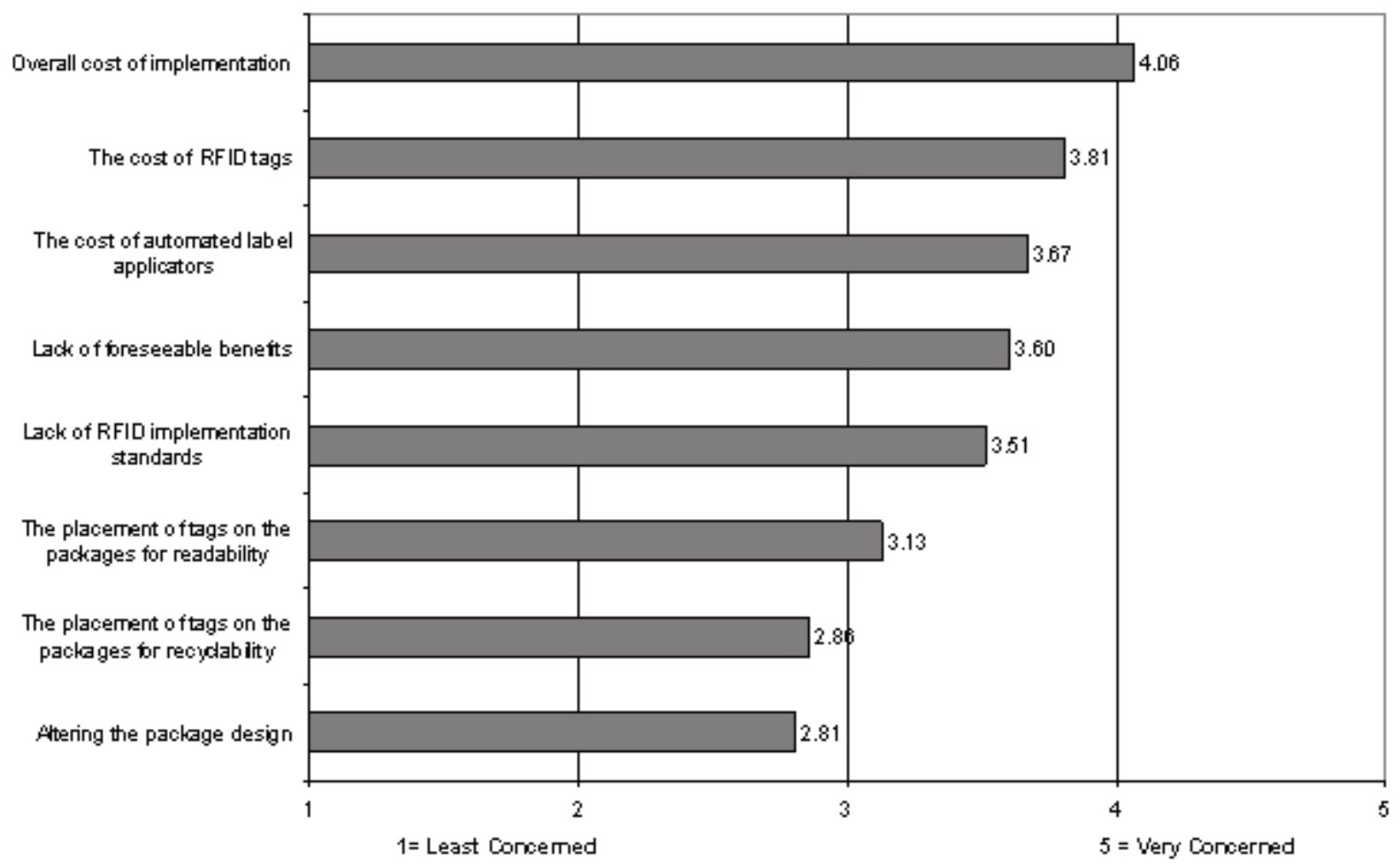

\section{Companies that are not considering RFID technology at present}

Slightly over half (52\%) of the companies surveyed are not considering RFID technology at present. A majority of these companies (70\%) expects to implement RFID in 2008 or beyond, and $24 \%$ of these companies think they would never implement RFID technology in their organization for their internal supply chain or integrating with their packaging materials. A majority of survey respondents see RFID technology adoption over the next few years. Lack of customer demand was the most important reason for these companies for not considering RFID implementation. Lack of standards, cost, lack of foreseeable benefits, and lack of understanding were other reasons for not considering RFID technology. Major concerns for these companies with respect to RFID technology were cost related, including the cost of implementation, the cost of tags, and the cost of automated label applicators. Other concerns that were somewhat important were lack of foreseeable benefits and lack of implementation standards. Altering the package design due to RFID implementation and the placement of tags on the packages for recyclability and readability were of the least concern (see Figure I). 
Figure 2: Reasons for Consiclering RFID

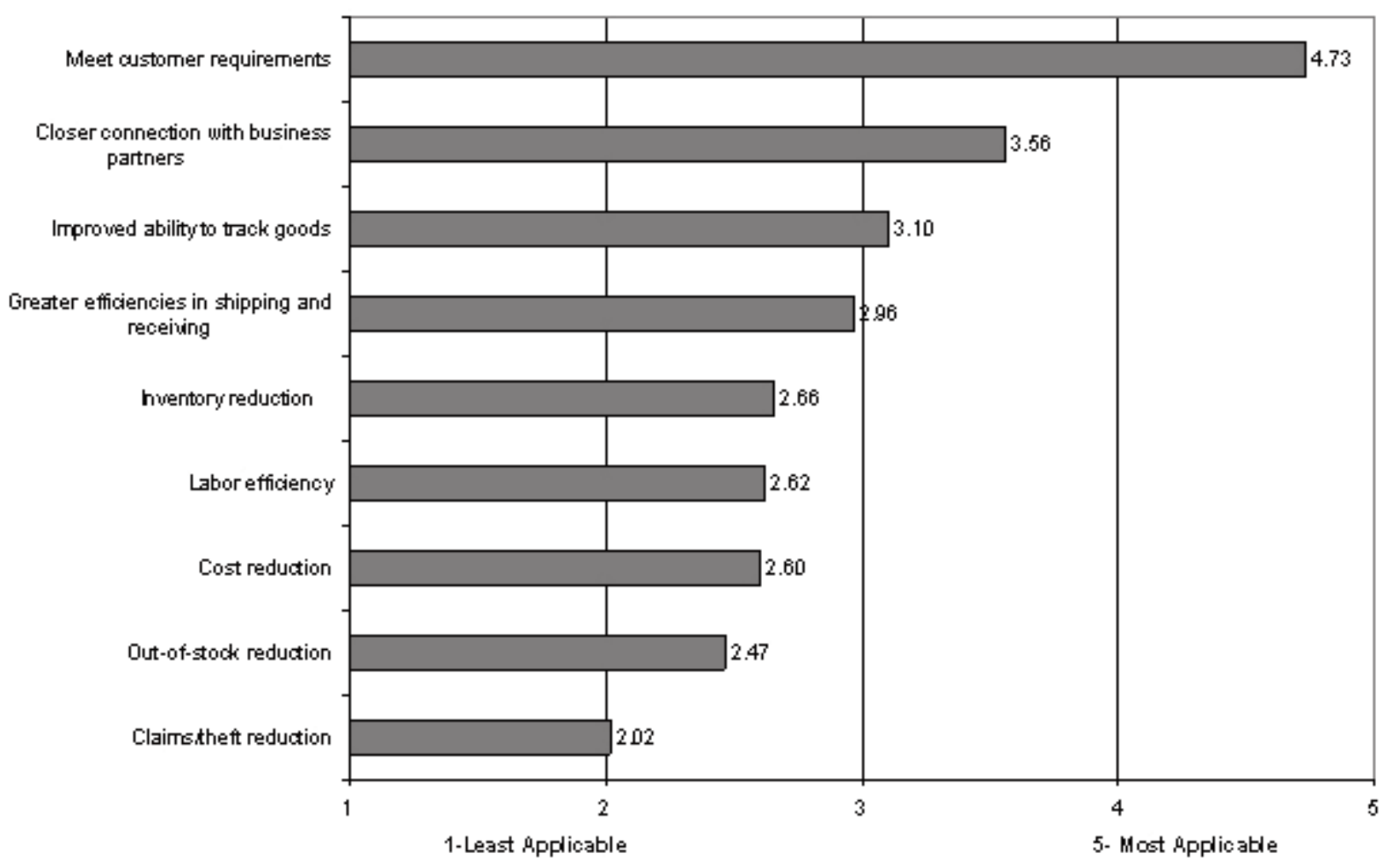

\section{Companies that are currently considering RFID tech- nology}

Thirty-six percent of the companies surveyed indicated that they are currently considering implementing RFID technology. Seventy-one percent of these respondents indicated the reason for considering RFID is to meet their customers' requirements and the rest $(29 \%)$ indicated the reason is to improve their internal supply chain efficiencies. When they were asked to rate the reasons on a scale of $I-5$, I being least applicable and 5 being most applicable, meeting their customer requirements ranked the highest (4.73) followed by a closer connection with business partners (3.56). Other reasons such as claims/theft reduction, out-of-stock reduction, inventory reduction were not rated very high. Reasons that improve internal supply chain efficiencies, such as improved ability to track goods and greater efficiency in shipping \& receiving were considered somewhat important. A majority of companies (57\%) that are considering RFID technology expect to implement RFID in less than 2 years (see Figure 2).

Many of these companies (75\%) are still doing initial research and gathering information on RFID systems, another $16 \%$ of these companies are doing cost justification and budgeting, $7 \%$ are developing a project plan, and only one company is at the stage of selecting a vendor. Five of these companies are expected to implement RFID technology is less than one year, 30 in one to two years, and the rest in more than two years. A majority of these companies expect that the RFID applications which help manage inventory services for customers would be the most beneficial reason for implementation, followed by package tracking. Other RFID applications such as raw material tracking, container tracking, component tracking, loss prevention, asset management and security are beneficial to a limited number of companies (see Figure 3). Many of these companies expect their RFID technology to be integrated with warehousing and supply chain applications and with IT infrastructure. The RFID solution will also be integrated with organization and IT strategy by many companies. Only a small number of companies expect their RFID application to be stand-alone.

When asked about the concerns they have with respect to issues related to RFID technology, several issues emerged as very important to these companies. Cost of implementation, cost of RFID tags, cost of automated label applicators, and lack of implementation standards all scored very high on the list of concerns (see Figure 4). Altering the package design and lack of foreseeable benefits were comparatively the least of their concerns. The placement of tags on the package for readability and 
Figure 3: Which of the Following RFID Applications will your Organization Benefit from?

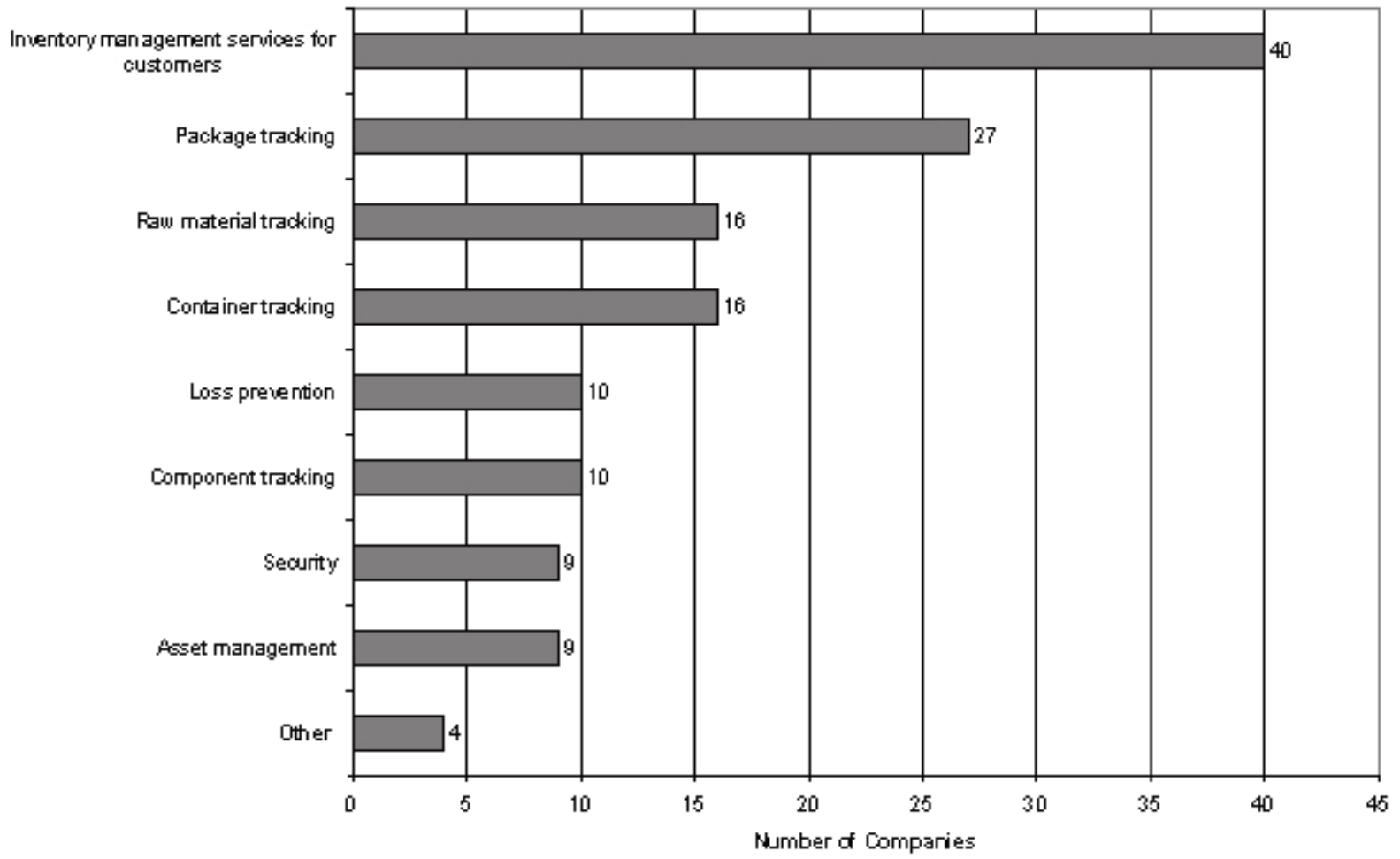

Figure 4: How concerned are you with the following issues related to the implementation of RFID Technology?

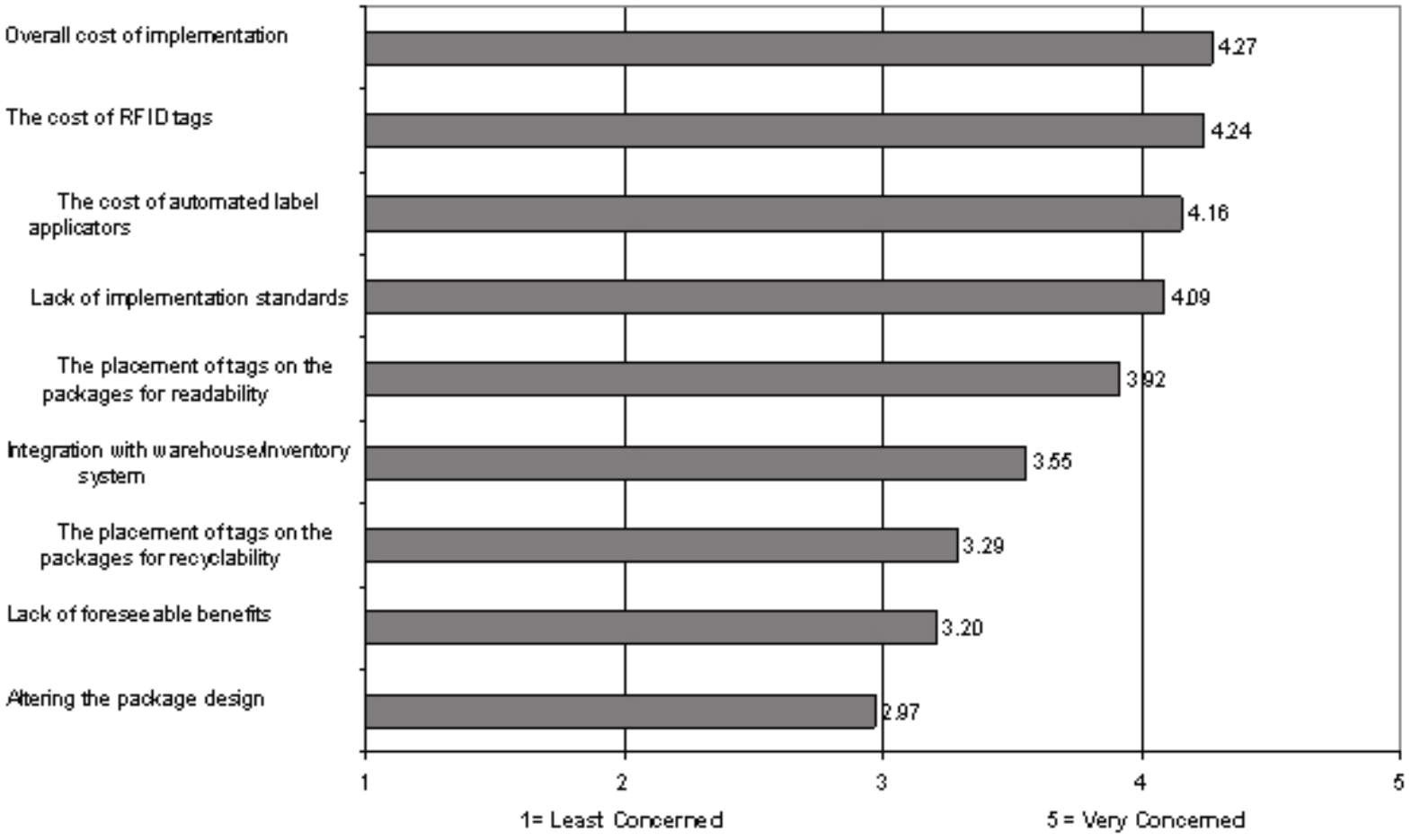


integration with warehouse and inventory systems were concerns to some extent. These concerns were very similar to the concerns of responding companies that are not considering RFID technology at present. Cost seems to be one of the biggest barriers to RFID implementation for many companies. Cutting the cost of RFID tags and the cost of implementation would be critical to widespread adoption of RFID technology.

\section{Companies that are pilot-testing/implementing RFID Technology}

A very small percentage of companies (I2\%) that responded to the survey are either pilot testing or implementing RFID technology. When these companies were asked for reasons for deploying RFID, meeting customer requirements was the overwhelming response. This is consistent with the findings of White, Johnson, and Wilson (2008), based on their survey of European supply chain managers. Seven companies also indicated "improvement to their supply chain efficiencies" as a reason for implementing RFID.

When asked to rate nine different reasons on a scale of I to 5 from least applicable to most applicable, meeting customer requirements was ranked the highest followed by closer connec-

Figure 5: Reasons for Deploying RFID - Companies Implementing RFID

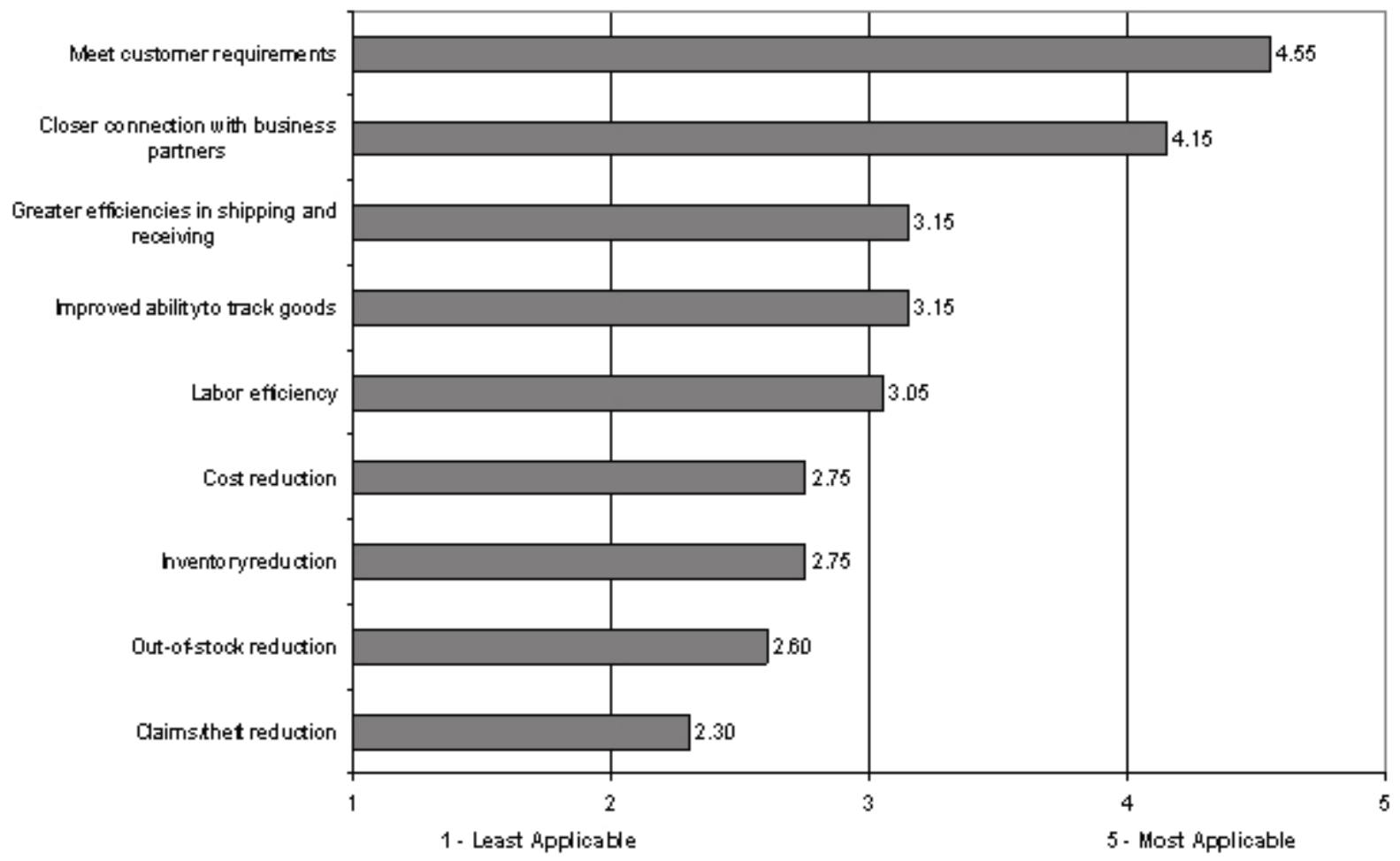

tion with business partners (see Figure 5). The least important reasons were claims/theft reduction, out-of-stock reduction, inventory reduction, and cost reduction. Reasons such as improved ability to track goods, greater efficiency in shipping and receiving, and labor efficiency were somewhat applicable. The reason for RFID deployment for many companies surveyed is still driven by customer requirements and not very much on improving internal supply chain efficiencies. These results were very similar to companies that are considering RFID technology.

The companies that are pilot testing/implementing RFID are at different stages of implementation with a small number of the companies having already purchased and developed the RFID systems. A majority of these companies are offering packages with applied RFID labels. Some of the major concerns of these companies were cost: cost of tags, cost of implementation, and cost of label applicators. The other major concern was the placement of tags on the packages for readability. Minor concerns were integration with warehouse/inventory systems, lack of implementation standards, and lack of foreseeable benefit. Altering the package design was at the bottom of the list of concerns (see Figure 6). 
Figure 6: Concerns Related to RFID Implementation

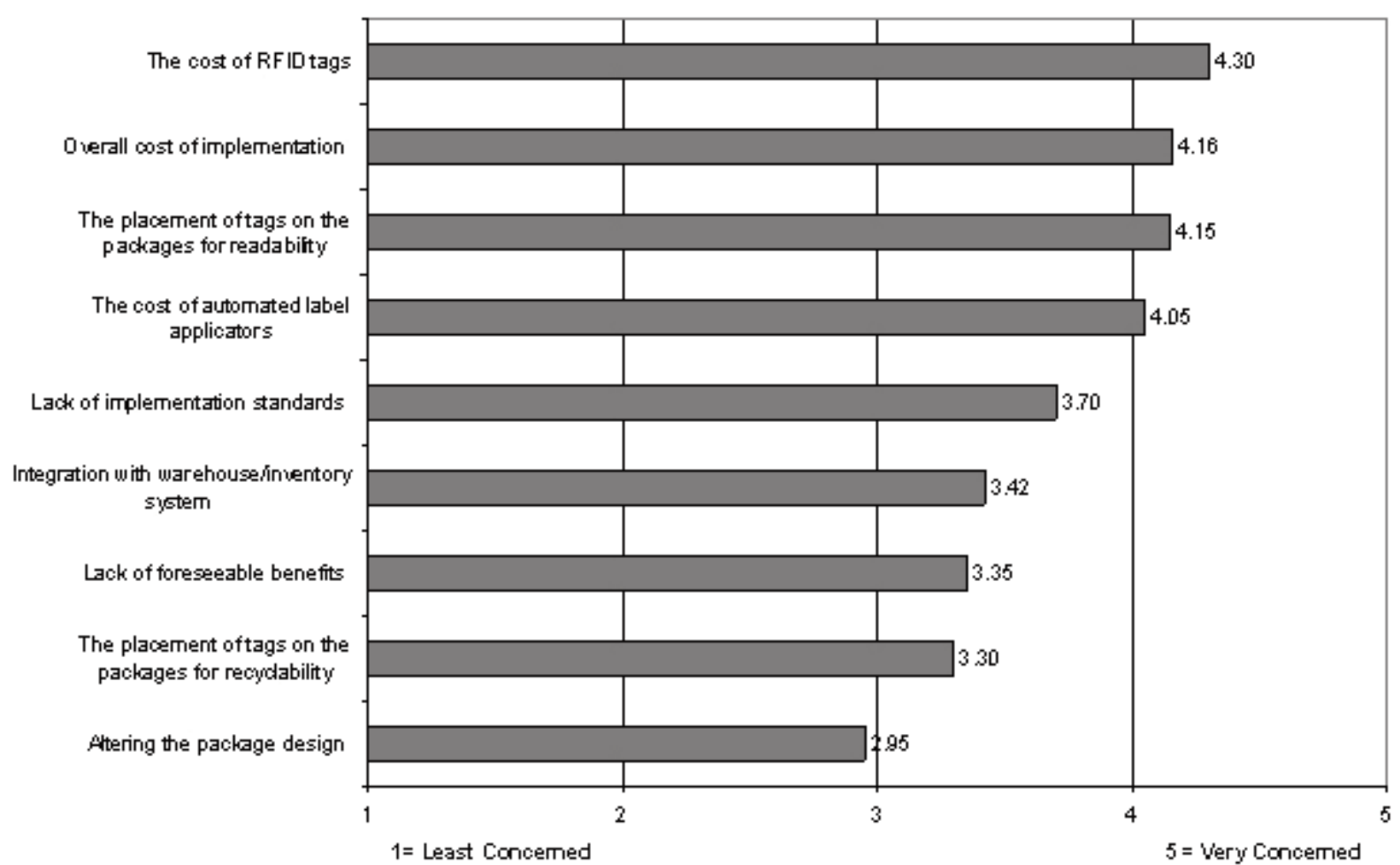

When asked about the time it takes to implement RFID, companies that are pilot testing indicated anywhere from 3 months to 6 months. These companies were also asked to indicate the types of problems they are experiencing in their pilot testing. Some of the problems these companies indicated are licensing, cost and general availability of tags, combining generation II tags with standard laser-printable paper labels, strength and durability of generation II tags, cost of implementation and variety of choices of RFID tags, and damage to tags/antenna during the application process.

Among the RFID applications that the organization benefit from the most, inventory management services for customers was ranked highest followed by package tracking. A handful of companies are expected to benefit from applications such as container tracking, asset management, loss prevention, raw material tracking and security. Only two companies indicated component tracking to benefit from RFID application.

With respect to integration of the RFID application with other systems, the majority of these companies are integrating with their current IT infrastructure followed by warehouse applications. A third of these companies are deploying RFID applications as stand-alone systems. Several companies expect to integrate their RFID applications with warehousing and SCM applications. Responding companies also indicated that their
RFID solution would be integrated with overall organizational and IT strategy.

Many of the companies that are pilot testing and implementing have a small budget for their RFID project. Five companies indicated that they are spending less than $\$ 100,000$ and 5 other companies indicated $\$ 100,000$ to $\$ 500,000$. Only one company is spending up to one million dollars and another company is spending more than 10 million dollars. These companies expect their cost savings to come from improved ability to track packages, out of stock reduction, and minimized inventory losses (see figure 7). Cost savings from a better ability to identify the source of defectives was at the bottom of the list.

Of the companies that responded to the question on anticipated savings from their RFID projects in the year after implementation, forty percent expected no savings at all. Another $40 \%$ indicated I to $5 \%$ savings and $15 \%$ indicated 6 to $10 \%$ savings. Only one company indicated savings of 11 to $15 \%$. Although not many companies are satisfied with RFID technology at this time (overall satisfaction of 3 on a scale of $I$ to 5 where $I$ is not satisfied and 5 is extremely satisfied), companies are somewhat pleased that they do not have to alter the design of the package. Security and integration with warehouse and inventory systems were high on the average satisfaction rankings. Respondents were less satisfied with the cost of RFID 
Figure 7: Where will the RFID cost savings c ome from?

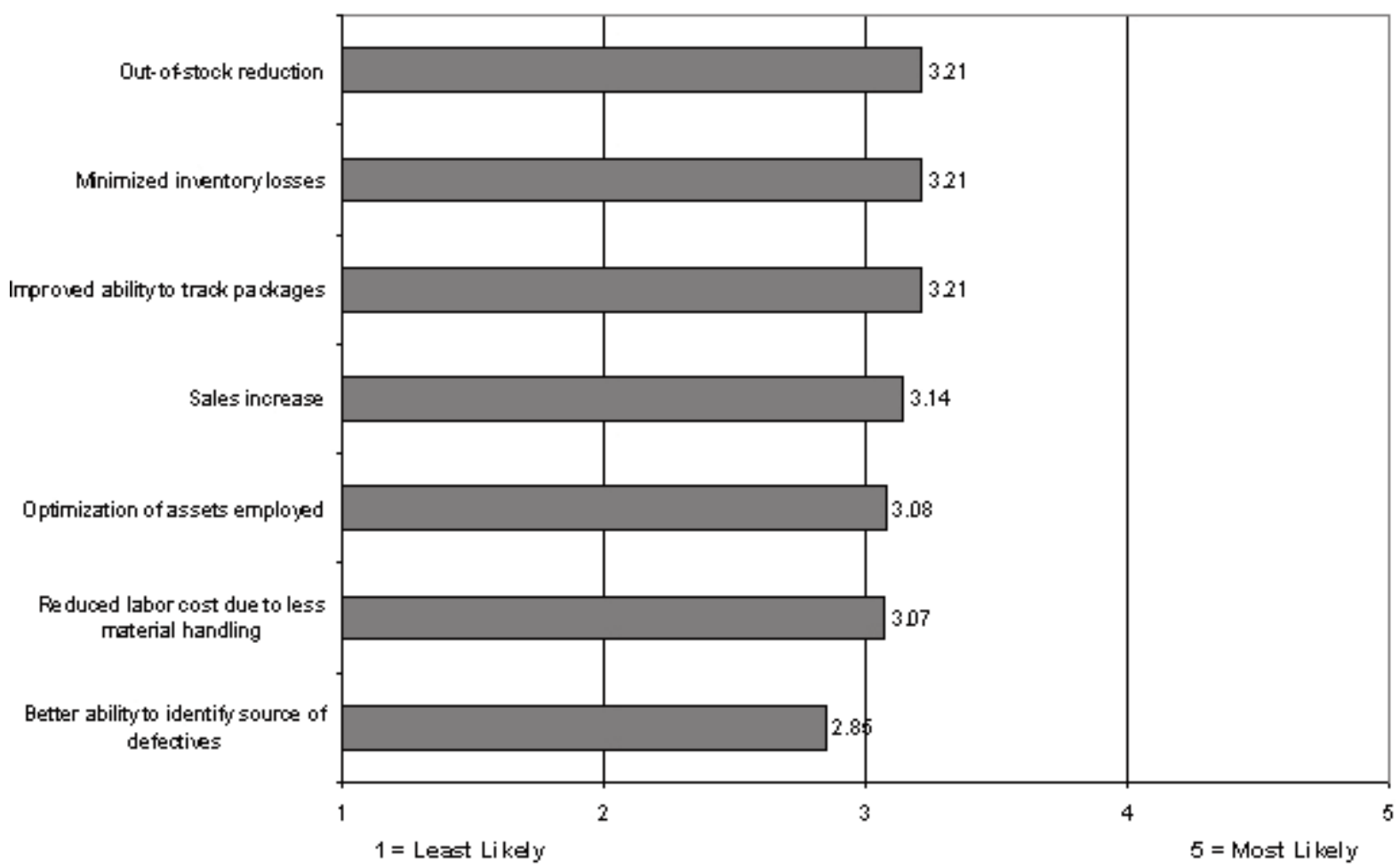

Figure 8: If your organization is using RFID, how satisfied are you, using the following reasons?

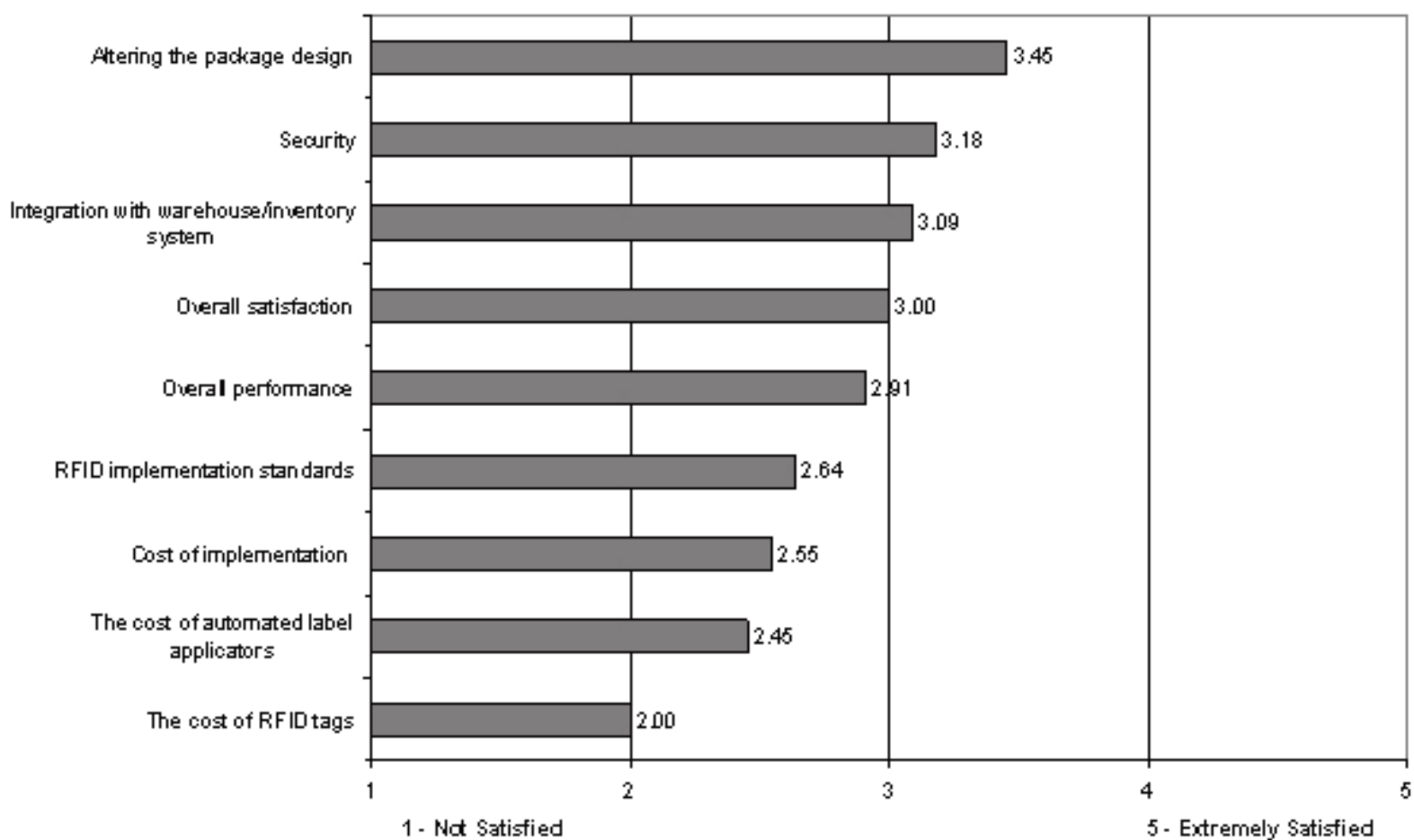


tags, automated applicators and overall implementation. Standards and overall performance also had satisfaction scores under 3 (see Figure 8).

When the companies were asked about the status of embedding or applying RFID tags on the packaging materials, only $9 \%$ of these respondents indicated that they are implementing it whereas $21 \%$ indicated that they are investigating it. Only 23\% of the companies have been contacted by RFID vendors or printing companies with an offer to embed RFID tags/labels into their packaging materials, whereas $32 \%$ of the companies have been contacted by customers about the possibility of implementing RFID tags into packaging material at the case, pallet or item level. Twenty-four percent of the companies indicated that their customers require them to embed RFID tag into the packing materials and $29 \%$ said embedding tags was not currently a customer requirement.

All of the survey participants were asked about their opinions on the future of RFID. There was a strong agreement among all the respondents that RFID implementation will add significant cost to their packaging operations. Respondents were neutral

Figure 9: Future of RFID

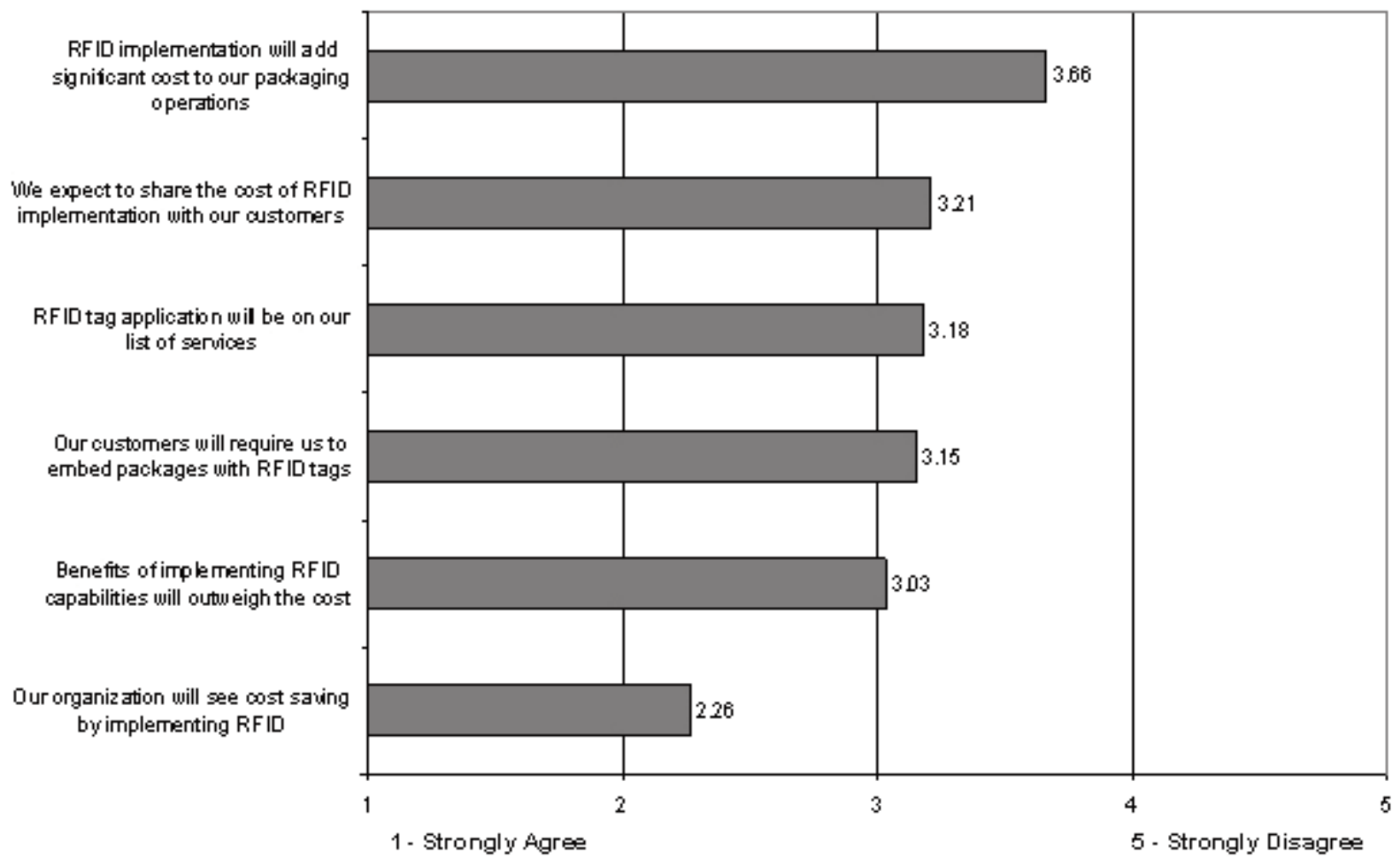

when it comes to benefits outweighing the cost of RFID implementation (see Figure 9). There were no statistically significant differences between the two groups: adopters and non-adopters on any of the issues presented to them.

When asked about their opinion on whether packaging converters should provide materials with RFID capabilities, 73\% said "yes" and the remaining $27 \%$ said "no." A majority of them (85\%) expect to share the cost of tag application with their business clients and only 15\% would absorb the cost by providing RFID tag application as a value-added service.

In response to a question on how RFID will affect the packag- ing design in the future, the responses varied significantly all the way from little impact to substantial impact. Some of the responses were:

- Consumers will need to be able to "kill" the tags for privacy reasons, making their usefulness questionable.

- $\quad$ Folding Cartons will not change much. The basic design neither helps nor hinders the application of an RFID tag or any other external/adhesive-applied thing, for that matter.

- Greater awareness of creating space, air gaps, rather 
than minimizing the packaging.

- I would think that a standard would be implemented where the tag is required to be on a specific panel of the carton.

- $\quad$ Making sure that tags are readable anywhere within a pallet load.

- $\quad$ RFID will cause packaging design revolution in future, like bar code.

- $\quad$ Relatively little impact in corrugated.

- $\quad$ Strongly feel that packaging designs will change to allow for RFID uses. Retail outlets are driving this application. They will need to be able to read the tags. If they cannot read the tags, redesigning the packaging will be an option.

- $\quad$ There must be specific positioning for RFID on the box, to be able to read it in auto mode.

- $\quad$ Simply put, it will be a requirement.

- $\quad$ Seamless transactions in warehousing and store fronts.

- Consideration will have to be given as to the position of the RFID at the early stages of design. Will revolutionize designs to implement RFID.

- $\quad$ Eventually, RFID will be implemented, more and more-in the future.

- I believe that it will strongly benefit companies with high inventory facilities and the keeping track of items in transit is just an added bonus.

- I think it is the future in shipping containers.

- Whether printed or applied designers will need to take RFID into account. It isn't necessarily bad for design to have an RFID requirement

Even though currently not many packaging companies are embedding RFID tags in their packaging, this will become increasingly important as retail companies start item level tracking and inventorying with smart displays. Many experts say that embedding RFID tags in the packaging, known as source tagging, will be the next revolution. Some big packaging manufacturers are conducting research in terms of the best way to integrate RFID tags in the packaging itself. NEC seems to have succeeded in embedding RFID tag in bottle cap and several banks are considering embedding RFID tags in banknotes. Our sample indicated a small percentage of respondents (9\%) are embedding RFID tags in the packaging whereas $21 \%$ indicated that they are investigating it and $32 \%$ of the companies have been contacted by customers about the possibility of implementing RFID tags into packaging material itself. This trend will increase as the cost of RFID tags drop in the future and retail companies start demanding manufacturers to tag at the item level. The major issue for embedding RFID tags in the package at the item level will be privacy concerns. This concern could be a big hindrance to widespread adoption of RFID tags at the item level.

The supply chain and packaging literature has suggested that technical and operational challenges will continue to exist and the current study confirms those concerns. RFID continues to hold much promise in a number of different packaging applications, including apparel, consumer goods, and produce (Singh, McCartney, Singh, and Clarke, 2008.) It has been suggested that it may be between two and five years before this industry sees significant demand from their customers for this technology (Albright, 2006). And it appears that packaging companies are investigating the likely benefits of RFID within their own facilities although not all are willing to share their "success stories."

\section{Implications and Conclusions}

Paperboard packaging converters that are either considering or implementing RFID are primarily doing so to meet customer requirements rather than to reduce cost or achieve supply chain efficiencies (see Figure 10). This is consistent with the results from other studies that surveyed retail, manufacturing, and warehouse industries (Bhattacharya, Chu, and Mullen, 2008; Vijayaraman and Osyk, 2006; White et. al. 2008) When RFID concerns were compared amongst all three groups (companies not considering, companies considering, and companies implementing), companies that are implementing were very concerned about the cost of RFID tags and the placement of tags on the packages for readability. For companies that are considering RFID, the overall cost of implementation, cost of automated label applicators, and lack of RFID implementation standards were of more concern. For companies that are not considering RFID, lack of foreseeable benefits was of more concern (see Figure II).

In conclusion, RFID continues to show much promise as a technology with many potential benefits across the supply chain. Previous research found that manufacturers are frequently piloting and adopting RFID initiatives in response to the mandates from their customers, especially those of Wal-Mart and other retailers (Whitaker, et. al. 2007). The current study confirms that this momentum is continuing to move back through 
Figure 10: Reasons for Implementing or Considering RFID

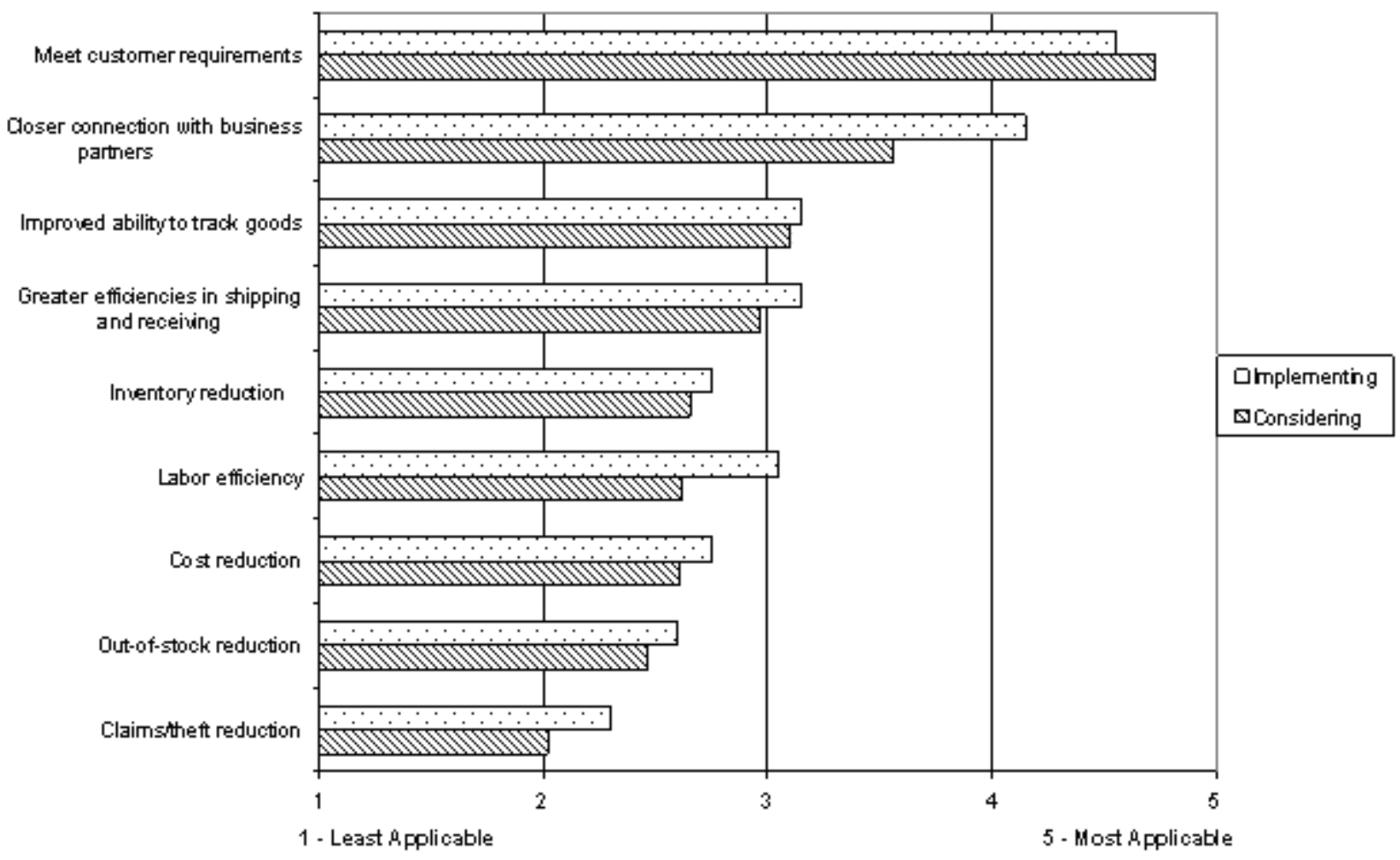

Figure 11: RFID Concems by Companies that are Implementing - Considering - Ilot Considering

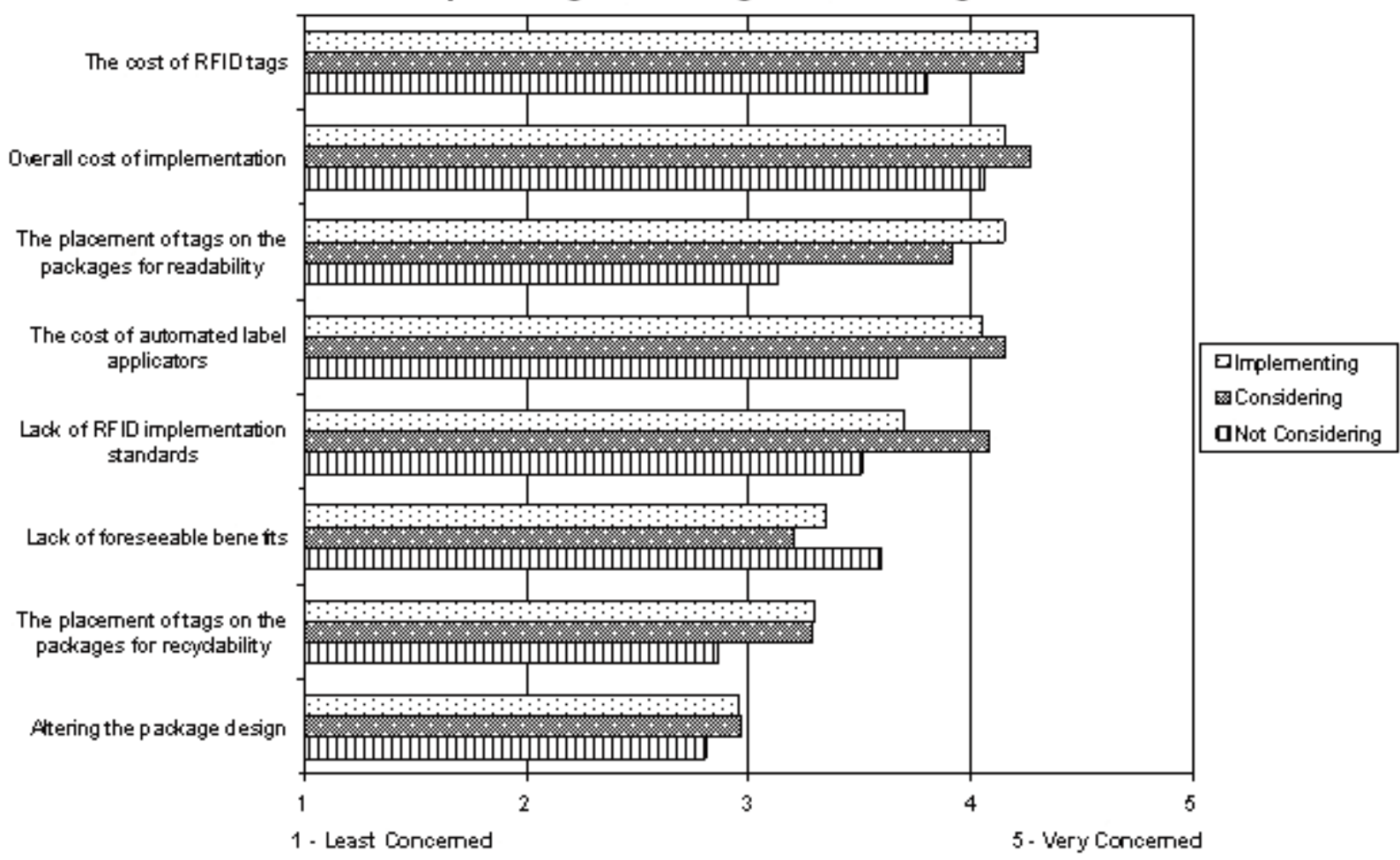


the supply chain. The Paperboard Packaging industry is beginning to implement this technology at the request of their customers, the manufacturers. Companies will be looking beyond meeting customer demand and will try to use RFID technology to improve their own operational efficiencies and reduce costs. In addition, RFID continues to show the promise as an integration tool to aid collaboration with others in the supply chain in an effort to reduce costs throughout the network (Fosso Wamba, et. al., 2007).

At present a number of concerns still exist that are limiting the widespread implementation of RFID in the Paperboard Packaging industry. Many in this industry are not yet ready to jump on the bandwagon and it appears that few expect a positive ROI any time soon. However, those in this industry that are implementing this technology (mostly very large companies) appear to be generally satisfied with their efforts thus far. Radio frequency identification is still viewed as an emerging technology, but one that will continue to have an increasing impact on the supply chain. The results of this study support the results of the earlier study conducted by Vijayaraman and Osyk (2006) and are consistent with the largely anecdotal case studies that have been reported in the literature. Even though RFID adoption rate is not increasing at a rate predicted by researchers several years ago, our research shows that RFID is growing at a steady rate. Rising interest in item level tagging coupled with cheaper tags and embedding of RFID tags in packaging will accelerate the adoption of RFID in the future.

\section{Limitations and Future Research}

This study had several limitations and there are many opportunities for future research. The survey was emailed to readers of a well-known packaging trade publication. However, not all paperboard packaging companies may have been represented in the distribution list. Also, the respondents represented a limited geographic area (U.S. based companies and a limited sample from Europe.) In addition, early adopters of RFID may consider this technology to be a competitive advantage and may be hesitant to share their experiences. At the time of the survey there were relatively few adopters of RFID technology in the packaging industry. As other researchers (White et. al., 2008; Whitaker et. al., 2007) have stated, this is a rapidly growing and fast moving field of research. The current study is largely based on respondent expectations of the benefits of RFID (including "expected" ROI) and not on actual results. In the future, as more organizations adopt RFID, researchers should be able to collect more data on the actual benefits realized by this technology.

\section{Acknowledgements}

The authors wish to thank Tom Andel, Paperboard Packaging magazine and FEFCO for their generous support of this project.

\section{References}

Aberdeen Group (2004). RFID in the Consumer Industries Benchmark Report. March 2004

Aberdeen Group (2006). The RFID Benchmark Report: Scaling RFID Implementations from Pilot to Production. June 2006.

ALBRIGHT, B. (2006). The RFID Conundrum, Paperboard Packaging, October 2006, 24-29.

ANDEL,T. (2005). Thinking RFID, Prove it, Paperboard Packaging. Retrieved from the Web I/30/2007.

http://www.packaging-online.com/paperboardpackaging/article/articleDetail.jsp?id= | 65946\&pageID $=2$

ANGELES, R. (2005). RFID Technologies: Supply-Chain Applications and Implementation Issues, Information Systems Management, 5I-65.

ASIF, Z. and, Mandviwalla, M. (2005). Integrating the supply chain with RFID:A technical and business analysis. Communications of the Association for Information Systems, I5, 393-427.

Clampitt, H. (2005). RFID vs Bar Codes. Retrieved from the Web 6/I/2007 http://www.idspackaging.com/Common/Paper/ Paper_165/Harold\%20G_\%20Clampitt\%20American\%20RFID_ Solutions.htm

CLARKE, R. H., Twede, D., Tazelaar, J. R., and Boyer, K. (2006). Radio Frequency Identification (RFID) Performance:The Effect of Tag Orientation and Package Contents. Packaging Technology and Science, 19,45-54.

DAS, R. (2007). RFID in 2006: A story of extremes, Packaging Digest, February, 44-46.

FERGUSON, R.B. (2004). Taking on RFID challenge. Eweek,April $5,12$.

HIDAKA, C. (2005). IBM Global Services. 90th Annual International Supply Management Conference, May 2005. 
HUGOS, Michael (2006). Essentials of Supply Chain Management, 2nd edition, John Wiley and Sons.

JONES, P., Clarke-Hill, C., Shears, P., Comfort, D. and Hillier, D. (2004). Radio frequency identification in the UK: Opportunities and challenges. International Journal of Retail \& Distribution Management, 32, 3, 164-171.

LEWIS, S. (2005). A Basic Introduction to RFID Technology and its Use in the Supply Chain, LARAN RFID White Paper.

MAHNA, R. (2005). Wireless in Packaging: RFID Technology, Applications and Implications. Italian Packaging Technology Awards. February 2005.

MARGULIUS, D. (2004). The Rush to RFID. Infoworld.com, April I2, 2004, 36-4I.

MORAN, H,Ayub, S., McFarlane, D. (2003). Improving Inventory Visibility in a Retail Company - Impact on Existing Procedures and Information Systems. Auto-ID Centre, January 2003.

MUMFORD, R. (2006). Microwave Journal, Vol. 49 No. 3, p 47. (AN 20227562)

NANOMARKETS, (2006). Smart Packaging Markets-2006-20I 3. Page 2

O'CONNOR, Mary Catherine (2006). TI, Smurfit-Stone Demo RFID-Enabled Cases, RFID Journal, March I, 2006.

PALMIERI, Marisa (2006). RFID: Ready or not. Paperboard Packaging. Retrieved from the Web 5/I/2006

http://www.packaging-online.com/paperboardpackaging/article/articleDetail.jsp?id= | 65946\&pagelD $=2$

POIRIER and McCollum (2006). RFID: Strategic Implementation and ROI, J. Ross Publishing, Florida,

RFid Gazette (2006). Smart Packaging Market to Reach $\$ 4.8$ billion by 20II. Retrieved from the Web 12/I/2006 http://www.rfidgazette.org/2006/04/index.html

ROBERTI, Mark (2006). RFID-Enabling the World's Packaging Infrastructure. RFID Journal, Retrieved from the Web I2/ //2006. http://www.rfidjournal.com/article/articleview/2795/

SINGH, S., M McCartney, J. Singh, and R. Clarke (2008). RFID
Research and Testing for Packages of Apparel, Consumer Goods and Fresh Produce in the Retail Distribution Environment. Packaging Technology and Science. 21, 91-102.

VIJAYARAMAN B.S., Osyk Barbara (2006). An Empirical Study of RFID Implementation in the Warehousing Industry. The International Journal of Logistics Management. I7, I, 6-20.

Warehousing Education and Research Council (2006). Compliance vs. ROI, Compelling reasons beyond compliance. WERC Sheet, October 2006, p. 10. 